American Journal of Pharmaceutical Education 2019; 83 (9) Article 7307.

\title{
BRIEF
}

\section{A Task Force on Recruitment, Admissions, and Retention to Improve Pharmacy College Admissions Outcomes}

\author{
Stacey D. Curtis, PharmD, ${ }^{\mathrm{a}}$ Carinda Feild, PharmD, ${ }^{\mathrm{b}}$ Shauna M. Buring, PharmD ${ }^{\mathrm{a}}$ \\ ${ }^{\text {a }}$ University of Florida, College of Pharmacy, Gainesville, Florida \\ ${ }^{\mathrm{b}}$ University of Florida, College of Pharmacy, Seminole, Florida \\ Submitted August 2, 2018; accepted April 19, 2019; published November 2019.
}

Objective. To create a task force on recruitment, admission, and retention, and assess pharmacy students' opinions and perceived value of the initiatives implemented.

Methods. A task force on recruitment, admission, and retention was created at the University of Florida College of Pharmacy to build relationships between the college and incoming students and improve the admissions process. Admission and retention initiatives were implemented over a three-year period. All applicants who received an offer of admission, whether they accepted or declined, were invited to complete an online survey designed to solicit feedback on the admissions and retention initiatives. Results. The response rate to the survey was $80.3 \%$ in 2016 and $85.7 \%$ in 2017 . The majority of students who responded reported that the admission and retention initiatives were helpful with regard to building connections with the college of pharmacy. In the three years after the task force implemented the admissions and retention initiatives, the admission yield (total number of students who accepted admission divided by the number offered admission) increased from $72.5 \%$ in 2015 to $79.5 \%$ in 2016 and $81.9 \%$ in 2017.

Conclusion. Development of a task force specifically aimed to build relationships with students accepted to the college through strategic initiatives was instrumental in increasing admission yield and reducing the number of applicants who initially accepted an offer of admission and then chose not to attend the college.

Keywords: recruitment, admission, retention

\section{INTRODUCTION}

Challenges exist throughout the academy related to a decline in the number of applicants to pharmacy school. In fall 2015, the national graduating high school student cohort was the smallest it had been in a decade. ${ }^{1}$ First-year undergraduate college enrollment declined nine percent from 2011-2016. ${ }^{2}$ The Pharmacy College Application Service (PharmCAS) saw a reduction in applicants from academic year of 2012-2013 total of $17,630^{3}$ to 16,176 in the academic year of 2016-2017. ${ }^{4}$ In contrast, the number of colleges and schools of pharmacy in the academic year of 2012-2013 totaled $110,{ }^{3}$ and is 142 as of $2018 .^{5}$ As the number of applicants declined and the number of colleges of pharmacy increased, colleges were faced with the challenge of attracting high-quality students.

The American Association of Colleges of Pharmacy (AACP) recognized this challenge and tasked the AACP Student Affairs Standing Committee with developing

Corresponding Author: Shauna M. Buring, 1225 Center Dr., HPNP Building, Room 4319, Gainesville, FL 32610. Tel: 352294-8426. Email: sburing@cop.ufl.edu. recommendations for recruitment to pharmacy and awareness of pharmacy careers. ${ }^{6}$ A literature review by the committee revealed that early education about the pharmacy profession aimed at high school students and parents may be helpful; however, they found limited data to document the effectiveness of particular initiatives. ${ }^{7-10}$ In addition to strategies aimed at increasing the pipeline, short-term strategies aimed at improving admission processes and attracting and retaining applicants already interested in the pharmacy program is another approach. Building authentic relationships with applicants and increasing touchpoints after a student has been admitted are proactive steps to maximize admission yield and minimize summer "melt." 11 The admission yield is the number of applicants who accepted admission divided by the number of applicants offered admission. "Melt" is the term given to the phenomenon in which an applicant who initially accepted an offer of admission and paid a deposit whom later declines to attend. With the decrease in pharmacy applicants, retaining students who have been offered admission becomes critically important. 


\section{American Journal of Pharmaceutical Education 2019; 83 (9) Article 7307.}

Retaining these students has been complicated by a lack of required cooperative admission guidelines among colleges that would potentially mitigate excessive admission melt resulting from applicants holding multiple acceptances. Data on admission melt in pharmacy is scarce. Hetrick and colleagues' presented a poster on the implementation of an enrollment management platform (EMP) with the purpose of decreasing melt and increasing yield. The EMP yielded an increase in seat deposits compared to the previous year despite a decrease in the total number of applications. ${ }^{12}$ The AACP Special Committee on Admissions recommended cooperative admission guidelines with a goal of decreasing extensive melt late in the admissions cycle. ${ }^{13}$ There was no literature describing comprehensive programs evaluating the entire admissions process (education, recruitment, and retention), nor looking specifically at retention initiatives in pharmacy admissions. Although there is a national initiative to improve melt, strategies are lacking on how to face the challenges associated with the decreasing number of applicants and applications in pharmacy. The goals of this study were to describe the development of the Recruitment, Admission, and Retention Task Force at the University of Florida College of Pharmacy outline task force initiatives focused on admissions and retention, and report the impact of these initiatives.

\section{METHODS}

Because of a shortfall in the number of admitted students who matriculated in fall 2015, the University of Florida College of Pharmacy (UF COP) developed the Recruitment, Admission and Retention Task Force. The purpose of the task force was to develop and implement strategies for recruitment, admission, and retention. The composition of the task force included a multidisciplinary team with representation from all four campuses: the Associate Dean for Clinical and Administrative Affairs, the Associate Dean for Student Affairs, assistant and associate professors, an admissions specialist, a recruiter, student affairs coordinators, and the Director of Communications. The task force met bi-weekly, with teleconferencing capabilities to facilitate participation for the distance campus members. An inclusive approach to brainstorming and planning was used where ideas were considered independent of task force members' position or rank. Early efforts focused on retaining applicants who initially accepted an offer of admission (ie, decreasing "melt"), with the long-term goals of expanding recruitment efforts and improving the admissions process.
The task force focused on developing initiatives that would build relationships with applicants. Over the next three years, the initiatives changed slightly as the task force implemented feedback solicited from students. The first initiative was to improve the experience of students on interview day. As of 2018, interview day consisted of candidates being given an introduction to the college provided by the dean, undergoing a 25 -minute interview with a team of two faculty members, taking a tour of the college, video conferencing with students at the college's distance campus, completing a problem-solving exercise, participating in a session on student life, watching an overview of the curriculum, and discussing financial aid. College of pharmacy student ambassadors were involved throughout the day and led the sessions on student life, curriculum, and problem solving.

The next initiative was sending a Welcome Packet to each applicant who was offered admission. The packet contained a signed letter from the dean welcoming the student to the UF COP, a UF flash drive containing important admissions information, a UF COP t-shirt, a UF COP car magnet, and a social media class card (used in 2016 only).

The third initiative was a communication plan focusing on building relationships by making personal phone calls to each student. In the first year this initiative was implemented, applicants received a phone call from either a faculty member or a student ambassador. In subsequent years, applicants received three phone calls: one each from their faculty interviewer, a student ambassador, and a UF COP alumnus. These phone calls occurred sequentially following the offer of admission. Every admitted student was contacted by phone or by email to arrange a phone call. One of the faculty members who interviewed the applicant called the student to welcome them to the college. The call served as an opportunity for applicants to ask additional questions and to further connect them to multiple stakeholders at the college. If a direct connection was not made, a brief message was left containing student affairs contact information. A student ambassador from the admitted student's assigned campus made a second phone call to the applicant. This call served as an opportunity for applicants to ask questions regarding more tangible information such as housing, course work, orientation activities, etc. A third phone call to each admitted student was made by an alumnus who welcomed them to the "Gator Nation." This phone call served to add an element of inclusion and help the applicant feel connected to the college on a more personal yet global level.

Last, in spring 2017, "Welcome to the Pharmily" (WTTP) events were added at each campus as a retention 


\section{American Journal of Pharmaceutical Education 2019; 83 (9) Article 7307.}

initiative. The WTTP events were planned by the student ambassadors and offered incoming students a glimpse of student life on the campus to which they were admitted. These events occurred March through July and provided students with an additional opportunity to connect with current students, ask questions, meet with a financial aid officer, tour the facilities, and meet faculty members.

A survey was created to measure the experiences and opinions of applicants who were interviewed for admission. The survey was designed to solicit feedback on the recruitment and retention initiatives (interview days, welcome packets, and call initiatives). Students were asked to rate statements regarding the different retention initiatives. The survey was administered in late summer and results were used to evaluate student perceptions of those initiatives. Minor edits were made to questions prior to administering the survey to students admitted in fall 2017. The University of Florida Institutional Review Board deemed the study exempt. The survey was sent to all individuals who were offered admission, regardless of whether they accepted the offer.

\section{RESULTS}

The survey was emailed to 346 students in 2016 and 278 in 2017 , with $80.3 \%$ and $85.7 \%$ of students responding, respectively. The majority of respondents, $92.8 \%$ in 2016 and $95.8 \%$ in 2017, indicated they would be attending the UF College of Pharmacy. Of the 71 students in 2016 and 35 students in 2017 who declined admission, $21.1 \%$ and $28.6 \%$, respectively, completed the survey. Applicant feedback on communication related to the application process and initiatives implemented to retain students after admission and through matriculation is presented in Table 1. Overall, students were in agreement that information from a variety of sources about the application process was useful.

Data on students' interview day experience are reported in Figure 1. Most aspects of the interview day were well received by students. The welcome packet was also well received by students (Figure 2). One component of the welcome packet, the social media class card, was removed after 2016 as students did not use it to create a social media post as intended.

In the 2016 survey, applicants were asked if the conversation and information from the call with the student and/or faculty member was helpful. Sixty percent agreed or strongly agreed with this statement and 33\% indicated they did not receive a call. In 2017, the survey was more granular and asked if the call from individual stakeholders positively influenced their decision to

Table 1. Feedback From Pharmacy College Applicants on Components of the Admission Process and Retention Initiatives

\begin{tabular}{|c|c|c|}
\hline Survey Item & $\begin{array}{l}2016 \text { Score }(\mathrm{N}=278), \\
\operatorname{Mean}(\mathrm{SD})^{\mathrm{a}}\end{array}$ & $\begin{array}{c}2017 \text { Score }(\mathrm{N}=238) \\
\text { Mean }(\mathrm{SD})^{\mathrm{a}}\end{array}$ \\
\hline $\begin{array}{l}\text { The College of Pharmacy website was a helpful source of } \\
\text { information regarding the application process to the } \\
\text { University of Florida, College of Pharmacy. }\end{array}$ & $3.5(0.5)$ & $3.5(0.6)$ \\
\hline $\begin{array}{l}\text { The "Contact Us" link on the University of Florida, } \\
\text { College of Pharmacy website was helpful because it } \\
\text { directly generated communication from the College of } \\
\text { Pharmacy with me. }\end{array}$ & $3.9(0.6)$ & $3.4(0.6)$ \\
\hline $\begin{array}{l}\text { The Student Affairs Office was helpful with answering } \\
\text { my questions regarding the application process for the } \\
\text { University of Florida, College of Pharmacy. }\end{array}$ & $3.5(0.5)$ & $3.5(0.6)$ \\
\hline $\begin{array}{l}\text { The Interview Day provided helpful information I } \\
\text { needed to make my decision to attend the University } \\
\text { of Florida, College of Pharmacy. }\end{array}$ & $3.7(0.53)$ & $3.7(0.5)$ \\
\hline $\begin{array}{l}\text { I received a welcome packet, which positively influenced } \\
\text { my decision to attend the University of Florida, } \\
\text { College of Pharmacy. }\end{array}$ & $2.9(1.4)^{\mathrm{b}}$ & $3.1(1.2)^{\mathrm{c}}$ \\
\hline $\begin{array}{l}\text { The Welcome to the Pharmily event positively } \\
\text { influenced my decision to attend the University of } \\
\text { Florida PharmD program. }\end{array}$ & $\mathrm{d}$ & $3.5(0.6)$ \\
\hline
\end{tabular}

${ }^{a}$ Responses based on a five-point Likert scale: $1=$ strongly disagree, $2=$ disagree, $3=$ agree, $4=$ strongly agree

b $2016=15.3 \%$ of respondents to the survey reported that they did not receive a packet

c $2017=9.5 \%$ of respondents to the survey reported that they did not receive a packet

d The "Welcome to the Pharmily" event was not included in the 2016 survey 


\section{American Journal of Pharmaceutical Education 2019; 83 (9) Article 7307.}

Interview Day Components

Dean's Welcome and Overview of the College

Inter actions w th the Student Ambassadors

Question and Answer Session

Student Life Session

Interview with Faculty

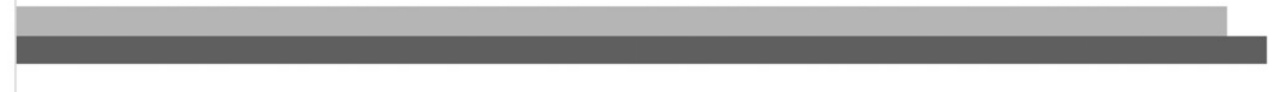

Guided Tour

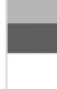

Financial Aid Discussion

Video Conference with Distance Campus Students

Problem Solving Exercise

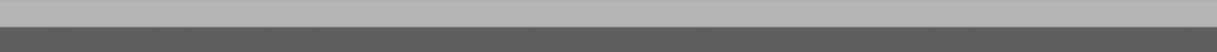

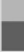

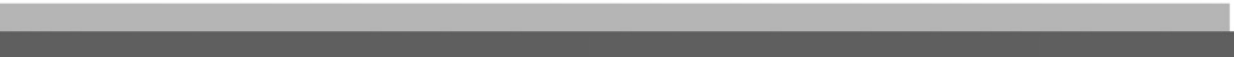

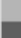

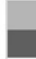
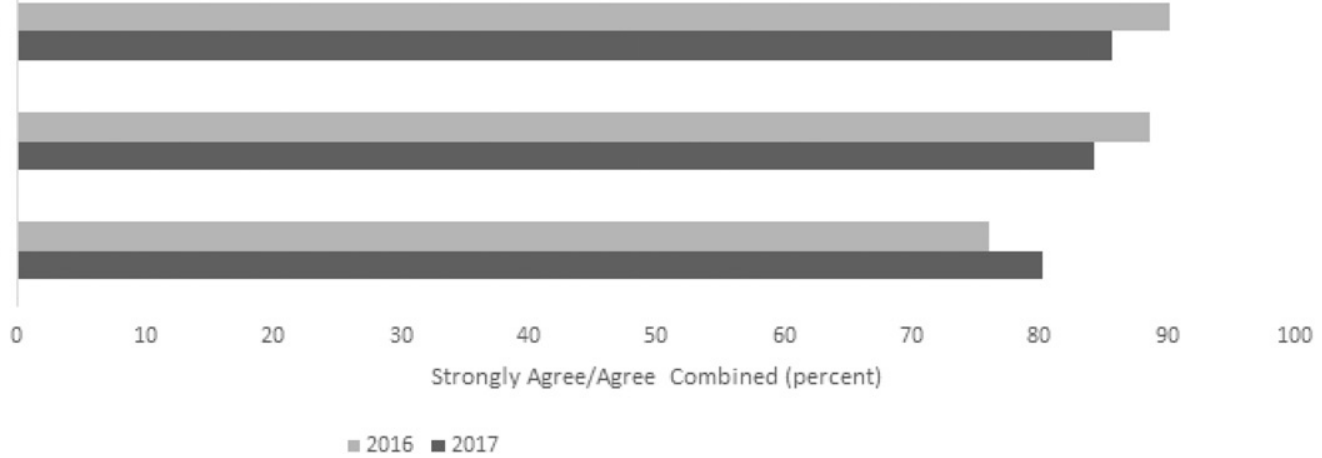

Figure 1. Percent of Applicants who Strongly Agreed or Agreed that a Specific Aspect of Interview Day was "Helpful in my Decision-making Process to Attend the UF College of Pharmacy"

attend. The majority of students responded positively that the phone calls from a faculty member $(79.8 \%)$, a current student (77.5\%), and an alumni member (67.2\%) had positively influenced their decision to attend UF.

Admission yield was calculated as a direct outcome measure to determine the initiatives' impact. Admission yield was defined as the number of applicants who accepted admission divided by the number of applicants offered admission. Admission yield fell from $84.4 \%$ in 2014 to $72.5 \%$ in 2015 . After implementation of retention initiatives, admission yield increased to $79.5 \%$ in 2017 and $81.9 \%$ in 2017 . Additionally, admission "melt" (ie, students who pay "seat deposits" but do not matriculate) decreased with each year of the task force: $55(19.4 \%)$ in 2015; 40 (12.7\%) in 2016; 29 (9.7\%) in 2017.

In $2017,93 \%$ of respondents indicated they felt connected to the UF PharmD program during the application process. Across the two years of the survey (2016 and 2017), 25 survey respondents indicated they chose not to attend the University of Florida. Reasons for declining the admission offer included tuition (six students), geography (six students), family/personal reasons (five students), and other reasons (16 students). Note that students could select more than one reason.

\section{DISCUSSION}

With the increase in the number of colleges of pharmacy and continuing decline in the number of applicants, optimizing offers of acceptance and retention of accepted students is critical. To maintain enrollment goals, colleges need to develop strategies to increase acceptance and retention rates without compromising admission standards. To our knowledge, this study was the first to examine the impact of such acceptance and retention initiatives in a college of pharmacy.

At the core of the initiative development and execution was the task force. The task force felt that a key to its success was both the multidisciplinary composition and the inclusive, non-hierarchical approach to bringing forth and considering strategies. Historically, committees and task forces were often comprised of faculty decisionmakers and supporting staff members. In contrast, every 


\section{American Journal of Pharmaceutical Education 2019; 83 (9) Article 7307.}

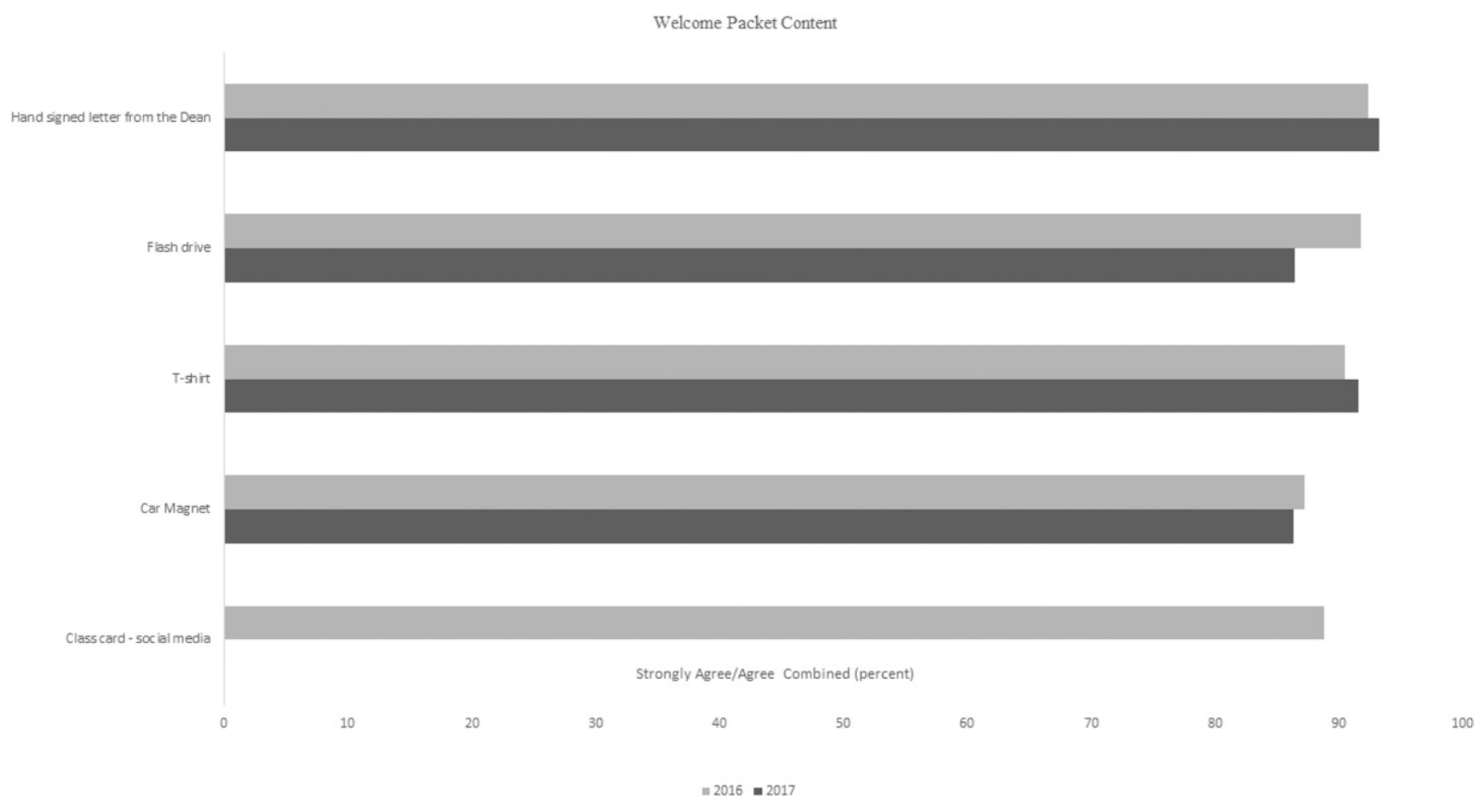

Figure 2. Percent of Applicants who Strongly Agreed or Agreed that a Specific Aspect of the Welcome Packet was "Helpful in my Decision-making Process to Attend the UF College of Pharmacy"

member of this task force was empowered to set aside role and rank and consider all ideas equally with each member having a vote. Approaches such as those identified by John Nance in the book Why Hospitals Should Fly were employed. ${ }^{14}$ In the book, Nance proposes that the medical industry would benefit from adopting the culture of the airline industry where everyone, regardless of position, is empowered to identify problems and bring forth solutions. The varied perspectives and knowledge brought by the diverse members of the task force allowed strategies and plans to develop more fully and comprehensively than they might have otherwise. The process worked well and the task force performed intermittent process improvement by obtaining feedback from all team members and adjusting process as needed.

Task force initiatives focused on connecting with students and developing relationships and this resulted in consecutive increases in application yield. The survey helped identify which initiatives were most impactful and led to modifications for the second year. Overall, the students responded well to interview and communication strategies designed to connect the student with the college and develop relationships. Connectedness was assessed the second year, with the overwhelming majority of applicants feeling connected to the program during the application process. Lack of connectedness was not cited as a reason for selecting another institution. These findings are consistent with literature advocating for a "people first," personalized approach to preventing summer melt of enrolled students. ${ }^{11}$ The survey revealed the initiatives implemented by the task force that decreased melt and increased the admissions yield over the past three years. The results of our study indicate that staying connected with students as a way to begin the relationship building process is critical to retaining students who have accepted admission.

Not all strategies were universally impactful as seen by accepted students' low usage of the social media class card. The intent of the social media class card was for the student to take a photo with the card indicating they were admitted to the class of 2020 and then post the picture to social media with the hashtag \#UFCOP2020. While almost $90 \%$ of students agreed or strongly agreed the social media card was helpful in making their decision, very few posted a picture to social media using the hashtag. Thus, in 2017 the social media class card was no longer included in the welcome packet. This might be explained by the way students use social media and how they use it to make connections. Based on input from student focus groups, students prefer to connect on social media independently without outside prompts to make connections. The phone calls to accepted students also had a variable positive 


\section{American Journal of Pharmaceutical Education 2019; 83 (9) Article 7307.}

response depending on which type of stakeholder was placing the call. Possible reasons for lower response to the alumni calls could be the wording of questions and the timing. The survey question specifically asked about calls even though several alumni reached out to students electronically, so response to alumni communication may not have been well captured. The alumni calls were one of the last retention initiatives to be implemented during the retention initiative process.

While the strategies implemented appear to have been beneficial, the study is not without limitations. Although the strategies were well received, the feedback does not allow determination of whether a particular strategy was more effective and whether it helped with acceptance or retention or both. Question design may have limited the ability to accurately capture the impact of the alumni-based calling program. These strategies are just one set of approaches to increasing admission and retention rates. There may be other programs and strategies that would be beneficial as well and work better for other institutional models (eg differences in timing of initiatives, two phases of tuition deposits, newsletter updates). More study in this area is needed to validate these findings and explore other options. In addition, it would be helpful to know which strategies were the most impactful to best target future programming and expand to other areas of the student acquisition process such as recruitment.

\section{CONCLUSION}

The development of a task force specifically focusing on building relationships through the recruitment, admission, and retention strategies was instrumental in identifying ways to increase admission yield and decrease melt. The interview day, welcome packet, phone calls from students, faculty members, and alumni and "Welcome to the Pharmily" events positively influenced students' decision to attend the UF College of Pharmacy. Using a multidisciplinary group of faculty and staff members may be useful for others in focusing on the specific challenges of recruiting a well-qualified class of students in an environment of increased competition. Further research on this topic could provide clarity on changes in admission practices and additional retention strategies to decrease admission melt.

\section{REFERENCES}

1. US Department of Education, Institute of Education Sciences, National Center for Education Statistics. Digest of Education Statistics. High school graduates, by sex and control of school: selected years, 1869-1870 through 2023-2024. http://nces.ed.gov/ programs/digest/d13/tables/dt13_219.10.asp. Accessed November 24, 2019.

2. US Department of Education, Institute of Education Sciences, National Center for Education Statistics. Undergraduate enrollment. http://nces.ed.gov/programs/coe/indicator_cha.asp. Accessed November 24, 2019.

3. 2013 American Association of Colleges of Pharmacy Annual Report. Am J Pharm Educ. 2013;77(10):Article S19.

4. Ross L. Student Affairs Update presented at: American Association of Colleges of Pharmacy Interim Meeting; February 24-27, 2018; Long Beach, CA.

5. American Association of Colleges of Pharmacy. Academic Pharmacy's Vital Statistics 2018. https://www.aacp.org/article/ academic-pharmacys-vital-statistics. Accessed November 24, 2019. 6. Chesnut RJ, Atcha II, Do DP, et al. Report of the 2016-2017 student affairs standing committee. Am J Pharm Educ.

2017;81(8):Article S12.

7. Anderson DC, Sheffield MC, Hill AM, Cobb HH. Influences on pharmacy students' decision to pursue a doctor of pharmacy degree. Am J Pharm Educ. 2008;72(2):Article 22.

8. Pitman EP, Masilamani S, Zaid S, Hatfield C, Coyle E. Recruiting Houston pharmd students: two pre-college pipeline programs. Am J Pharm Educ. 2016;80(5):Article S2.

9. Langridge SM, Stensland SL, Warholak TL, Mattingly L. Impact of the career explorers program on high school students' perceptions of the pharmacy profession. Am J Pharm Educ. 2009;72(3):Article 68.

10. Goldsmith C, Tran TT, Tran L. An educational program for underserved middle school students to encourage pursuit of pharmacy and other health science careers. Am J Pharm Educ.

2014;78(9):Article167.

11. Warding off Summer Melt. Inside Higher Ed. https://www. insidehighered.com/blogs/call-action-marketing-and-communicationshigher-education/warding-summer-melt. Accessed November 24, 2019.

12. Hetrick GB, Jones KA, Brooks T, Henriksen JA, Bonnarens, JK. Implementation of an enrollment management platform (EMP) to enhance candidate yield during the admissions cycle. Poster presented at: American Association of Colleges of Pharmacy Annual Meeting; July 23-27, 2016; Anaheim, CA.

13. Wall AL, Aljets A, Ellis SC, et al. White paper on pharmacy admissions: developing a diverse work force to meet the health-care needs of an increasingly diverse society. Am J Pharm Educ. 2015;79(7):Article S7.

14. Nance JJ. Why Hospitals Should Fly: The Ultimate Flight Plan to Patient Safety and Quality Care. Bozeman: Second River Healthcare. 2008. 